\title{
Floresta - utilização de produtos de madeira
}

\author{
Antônio de A. Corrêa * \\ Cleusa Maria Corrêa*
}

A "Hiléia", de Humboldt e Bompland, formada pelas matas densas da imensa bacia dos rios Amazonas e alto Orinoco, constitui a mais extensa área de floresta do mundo.

A parte brasileira deste maciço, na sua maioria, apresenta uma topografia plana ou um poucc ondulada, altamente favorável à sua valorização.

A bacia amazônica é também servida por uma rede considerável de rios navegáveis: navios transatlânticos podem percorrer 8.000 $\mathrm{km}$ desta rede no próprio Brasil, enquanto que navios de menor calado tem oportunidade de servir uma hinterlândia ainda maior.

A esse respeito, pode-se dizer que é difícil encontrar melhores condições em qualquer outra parte do mundo tropical.

Considerando, por outro lado, os índices um tanto alarmantes do crescimento demográfico das populações humanas, e o consumo crescente de produtos madeireiros "per capita", é quase inelutável que os potenciais produtivos da "Hiléia" não pocierão deixar de participar cada vez mais da economia florestal, tanto nacional como mundial.

Daí a necessidade de desenvolver métodos que assegurem uma valorização do patrimônio florestal e que obedeçam aos princípios de conservação e da renovação destes recursos naturais (Dubois, 1967).

A despeito do potencial madeireiro e das facilidades geográficas que a região oferece, o aproveitamento industrial desta matéria-prima é insignificante sem nenhuma integração, acarretando desperdício considerável.

Por outro lado, a possibilidade do aproveitamento industrial da grande maioria das madeiras da Amazônia, tem sido questionado, em decorrência de inúmeros fatores, entre os quais a falta de melhores e maiores conhecimentos que possibilitam avaliar as caracterís-

ticas e as qualidades das madeiras da região e que viabilizam o seu aproveitamento. Em face desta situação, a agropecuária tem-se apresentado como melhor alternativa para o empresário, levando grandes superfícies florestais a serem sacrificadas para transformação em campos de pastagem.

No Quadro 1, apresentamos dados que ilustram a não integração das indústrias florestais da Amazônia, assim como o desperdício de madeiras causado por empreendimentos agropecuários.

QUADRO I

Disponibilidade anual de madeiras na Amazônia.

\begin{tabular}{c|c|c}
\hline Matéria-prima & $\begin{array}{c}1.000 \mathrm{~m}^{3} \\
\text { Quant. anual }\end{array}$ & $\%$ \\
\hline Resíduos Industriais $\ldots \ldots \ldots \ldots \ldots$ & 2.500. & 1.4 \\
Residuos de Exportação $\ldots \ldots \ldots$ & 50.000. & 28.1 \\
$\begin{array}{r}\text { Residuos de Projetos Agropecuá- } \\
\text { rios } \ldots \ldots \ldots \ldots \ldots \ldots \ldots \ldots \ldots \ldots\end{array}$ & $\begin{array}{c}125.000 . \\
177.500 .\end{array}$ & $\begin{array}{c}70,5 \\
100,00\end{array}$ \\
\hline
\end{tabular}

FONTE : Guerro, 1977.

No que diz respeito ao baixo aproveitamento industrial da floresta amazônica, é suficiente considerar que esta área, representando cerca de $80 \%$ das florestas brasileiras, participou em 1972 , com apenas $12 \%$ de madeiras em toras (Quadro II) em decorrência de apenas uma área muito restrita da floresta ser explorada. Cerca de dois terços da produção amazônica provém da parte leste do Estado do Pará, na região limitada pela ilha de Marajó, às margens do rio Xingu e das estradas Belém-Brasília e Transamazônica. A terça parte restante provém essencialmente da floresta situada ao longo dos rios amazônicos a montante de Manaus (Volatron, 1976). 
QUADRO II

Produção de madeiras industriais, 1972.

(em milhões de $\mathrm{m}^{3}$ )

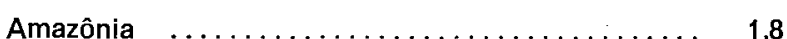

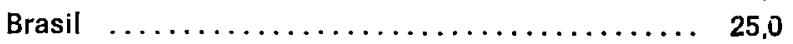

FONTE: Volatron, 1976.

Assim, mais de $80 \%$ da produção provém das florestas de várzeas, florestas de terras inundáveis. No que concerne a esta exploração, somente uma parte da floresta de várzea é utilizada, compreendendo as áreas situadas ao longo dos cursos d'água com penetração de 300 a 400 metros para o interior, restando, quase toda a floresta de terra firme incólume à exploração (idem) .

Em contrapartida, o número de espécies de madeiras da Amazônia que são beneficiadas industrialmente é muito reduzido, como pode ser verificado no Quadro III

QUADRO III

Essências utilizadas na indústria madeireira na Amazônia, 1972.

\begin{tabular}{|c|c|c|c|}
\hline Nome vulgar & $\begin{array}{c}\text { Volume em } \\
1.000 \mathrm{~m}^{3}\end{array}$ & $\%$ & $\begin{array}{c}\% \\
\text { acumulado }\end{array}$ \\
\hline Virola (Ucuuba) & 878,02 & 38,0 & 38,0 \\
\hline Mogno (Aguano) ..... & 201,87 & 8,7 & 46,7 \\
\hline Andiroba $\ldots \ldots \ldots \ldots$ & 150,78 & 6,5 & 53,2 \\
\hline Louro Inhamuí $\ldots .$. & 148,64 & 6,4 & 59,6 \\
\hline Cedro $\ldots \ldots \ldots \ldots \ldots$ & 107,01 & 4,6 & 64,2 \\
\hline Andiroba $\ldots \ldots \ldots \ldots$ & 99,09 & 4,3 & 68,2 \\
\hline Maçaranduba $\ldots \ldots \ldots$ & 55,94 & 2,4 & 70,9 \\
\hline Sucupira ........... & 48,10 & 2,1 & 73,0 \\
\hline Fau Amarelo ........ & 42,63 & 1,8 & 74,8 \\
\hline Assacu $\ldots \ldots \ldots \ldots$ & 40,62 & 1,8 & 76,6 \\
\hline Louro $\ldots \ldots \ldots \ldots$ & 35,65 & 1,5 & 78,1 \\
\hline Jacareúba $\ldots \ldots \ldots \ldots$ & 32,61 & 1,4 & 79,5 \\
\hline Quaruba $\ldots \ldots \ldots \ldots$ & 28,32 & 1,2 & 80,7 \\
\hline Cupiúba $\ldots \ldots \ldots \ldots$ & 26,97 & 1,2 & 81,9 \\
\hline Piquiá $\ldots \ldots \ldots \ldots \ldots$ & 26,54 & 1,1 & 83,0 \\
\hline Freijó $\ldots \ldots \ldots \ldots \ldots$ & 24,29 & 1,1 & 84,1 \\
\hline Pau d'arco (Ipê)....... & 23,53 & 1,0 & 85,1 \\
\hline Marupá $\quad \ldots \ldots \ldots \ldots$ & 22,16 & 1,0 & 86,1 \\
\hline Jatobá $\ldots \ldots \ldots \ldots \ldots$ & 19,25 & 0,8 & 86,9 \\
\hline Acapu $\ldots \ldots$. & 18,75 & 0,8 & 87,7 \\
\hline Angelim Pedra & 18,60 & 0,8 & 88,5 \\
\hline Louro Preto ......... & 17,64 & 0,8 & 89,3 \\
\hline Cerejeira $\ldots \ldots \ldots \ldots$ & 16,35 & 0,7 & 90,0 \\
\hline Outras essências ..... & 227,38 & 10,0 & 100,0 \\
\hline Total. & $2.310,97$ & 100,0 & - \\
\hline
\end{tabular}

FONTE : Volatron, 1976
Esta situação mostra que a região mal deu início ao aproveitamento dos seus recursos florestais, no conceito da moderna tecnologia, em dimensão suficiente, que propicie o aproveitamento de economia de escala.

\section{A IMPORTÂNCIA DO EXTRATIVISMO VEGETAL}

\section{EXPLORAÇÃo MADEIREIRA NA ECONOMIA}

REGIONAL AMAZÔNICA

Uma das mais tradicionais e importantes atividades econômicas na região amazônica é a exploração madeireira, que dentro do extrativismo vegetal, tem contribuído em larga escala para a economia regional durante todos estes séculos, muito embora, não tenha havido grandes inovaçōes e progressos nos métodos de exploração e extração, bem como conhecimento de seu potencial de ocorrência e tecnológico, para o melhor e mais racional aproveitamento dessa matéria-prima.

Inúmeros fatores contribuem para essa incipiência, impedindo um maior dinamismo desse setor sendo talvez o mais grave a falta de pesquisa intensiva e sistemática com a divulgação periódica dos resultados para promover o real conhecimento dessa fonte de rique$z a$, quer no aspecto científico e tecnológico, quer no econômico e social.

Um dos grandes entraves apontados pelo presidente da Sociedade Brasileira de Silvicultura, Sérgio Lupatelli, é a falta de definição de um programa global para o setor, unificação nos trabalhos de pesquisas e sincronizações entre os diversos órgãos de pesquisa sob uma coordenação central para que se estabeleçam metas e planos de ação (Madeira..., 1978) .

\section{O COMPORTAMENTO DO SETOR}

Os inventários florestais realizados na Amazônia estimam o potencial médio de madeira em pé em $178 \mathrm{~m}^{3} / \mathrm{ha}$ na terra firme $\left(45,123\right.$ milhões de $\left.\mathrm{m}^{3}\right)$ e $90 \mathrm{~m}^{3} /$ ha na várzea (585 milhões de $\mathrm{m}^{3}$ ) o que leva a um potencial global superior a 45,7 bilhões de $\mathrm{m}^{3}$. 
Porém, considerando que nem todas as madeiras amazônicas são conhecidas nos mercados, estima-se um potencial médio de madeiras comercializáveis com o diâmetro igual ou superior a $45 \mathrm{~cm}$ DAP, na ordem de $60 \mathrm{~m}^{3}$ / ha na terra firme e $30 \mathrm{~m}^{3} / \mathrm{ha}$ na várzea (SUDAM s/d - a).

Em termos perspectivos, tomando-se por base as exportações de não coniferas em 1970 $e$ as taxas de crescimento anuais relativas às taxas e derivados da mesma categoria de madeira, pode estimar-se para 1985 a seguinte demanda potencial (SUDAM, 1973b).

Toros de não coníferas ... Serrados da mesma catego-

$\begin{array}{lr}\text { ria } \ldots \ldots \ldots \ldots \ldots \ldots & 13.000 .000 \mathrm{~m}^{3} \\ \text { Laminados } \ldots \ldots \ldots \ldots \ldots & 4.700 .000 \mathrm{~m}^{3} \\ \text { Compensados } \ldots \ldots \ldots \ldots & 20.000 .000 \mathrm{~m}^{3}\end{array}$

Segundo dados da SERET S/A, em 1972 (SUDAM, 1973c), o consumo de madeiras em toros pelas 225 serrarias existentes na Amazônia foi da ordem de $1.962 .086 \mathrm{~m}^{3} /$ ano de madeira bruta gerando uma produção de cerca de $981.000 \mathrm{~m}^{3}$ de serrados dando um aproveitamento médio de $50 \%$ da matéria-prima processada, o que representa baixo índice de eficiência em comparação com outros estabelecimentos similares situados fora da Amazônia que conseguem operar com 65 a $70 \%$ de aproveitamento .

Uma grande parte dessas serrarias ainda trabalha com equipamentos obsoletos, mal distribuídos, com fornecimento deficiente de energia e ainda usa, como forma correta de secagem, a natural, ao ar livre, em "tesoura" ou com empilhagem horizontal das tábuas, 0 que exige prazos de 2 a 3 meses para a redução de $20 \%$ da umidade, criando grandes dificuldades de capital de giro, dado o demorado período de processamento (SUDAM, 1973c).

A extração madeireira na Amazônia localiza-se principalmente nas várzeas, terras inundáveis, localizadas às margens dos rios, embora estas representem apenas $1 \%$ do complexo florestal amazônico, fato que se explica pela maior facilidade de transporte dos toros por flutuação, amarrados em jangadas. No que concerne à exploração das matas de terra firme, sabe-se que a mecanização resolveria tecnicamente o problema, mas a incidência desta sobre o custo da matéria-prima ainda é desconhecida, no que diz respeito à maioria dos tipos florestais de terra firme (EMBRAPA, 1974) .

Atualmente, existe na Amazônia Legal cerca de 300 serrarias. Perto de $70 \%$ da produção são obtidas em $20 \%$ das instalações concentradas principalmente nas áreas de Belém e Manaus. No setor de laminados, existem 15 empresas com uma produção de $250 \mathrm{mil} \mathrm{m}^{3}$ / ano.

As empresas fabricantes de laminados são, em geral, mais modernas e usam espécies mais diversificadas, embora ainda estejam longe de utilizar todas as espécies disponíveis.

A produtividade média na Amazônia Legal não passa de $0,5 \mathrm{~m}^{3}$ diário/homem, enquanto a produção mecanizada pode chegar a $17 \mathrm{~m}^{3}$ diário/homem e até mesmo a $50 \mathrm{~m}^{3}$ diário/ homem (Madeira, etc... 1978).

Cerca de $90 \%$ do volume de madeira extraída na região são explorados manualmente.

Das serrarias atuantes na Amazônia, 65\% não possuem matas próprias; as operações de derrubadas, extração e transporte são executadas por terceiros. A extração é feita mediante incursões de reconhecimento pela mata e posterior "catação" das árvores localizadas em posições acessíveis.

\section{CONSUMO, PRODUÇÃo E EXPORTAÇÃo}

O consumo "per capita" de madeiras no Brasil é bastante insignificante quando comparado com outros países (Quadro IV).

O consumo do Canadá, um dos maiores, é de $5,79 \mathrm{~m}^{3}$, sendo $98 \%$ maior do que o consumo brasileiro que é de $0,096 \mathrm{~m}^{3}$, o qual é mais baixo do que o da Africa do Sul que é de $0,52 \mathrm{~m}^{3}$. Uma das principais razões desse baixo nível de consumo é a falta de conhecimento e divulgação sobre o seu uso, tais como a classificação da madeira segundo sua aplicação, produção e usos de elementos pré-fa- 
QUADRO IV

Consumo per capita de madeiras em alguns países.

\begin{tabular}{|c|c|}
\hline Países & Consumo \\
\hline Canadá & $5,79 \mathrm{~m}^{3}$ \\
\hline EUA $\ldots \ldots \ldots \ldots \ldots \ldots \ldots \ldots \ldots$ & $1,48 \mathrm{~m}^{3}$ \\
\hline Austrália $\quad \ldots \ldots \ldots \ldots \ldots \ldots \ldots$ & $1,23 \mathrm{~m}^{3}$ \\
\hline URSS $\ldots \ldots \ldots \ldots \ldots \ldots \ldots \ldots \ldots$ & $1,18 \mathrm{~m}^{3}$ \\
\hline Japăo $\ldots \ldots \ldots \ldots \ldots \ldots \ldots \ldots \ldots$ & $1,03 \mathrm{~m}^{3}$ \\
\hline Noruega $\ldots \ldots \ldots \ldots \ldots \ldots \ldots \ldots$ & $0,90 \mathrm{~m}^{3}$ \\
\hline Inglaterra $\ldots \ldots \ldots \ldots \ldots \ldots \ldots$ & $0,77 \mathrm{~m}^{3}$ \\
\hline Alemanha Ocidental $\ldots \ldots \ldots \ldots \ldots \ldots$ & $0,60 \mathrm{~m}^{3}$ \\
\hline Itália $\ldots \ldots \ldots \ldots \ldots \ldots \ldots \ldots$ & $0,60 \mathrm{~m}^{3}$ \\
\hline Africa do Sul $\ldots \ldots \ldots \ldots \ldots \ldots$ & $0,52 \mathrm{~m}^{3}$ \\
\hline Chile $\ldots \ldots \ldots \ldots \ldots \ldots \ldots \ldots$ & $0,40 \mathrm{~m}^{3}$ \\
\hline Argentina $\quad \ldots \ldots \ldots \ldots \ldots \ldots \ldots$ & $0,14 \mathrm{~m}^{3}$ \\
\hline México $\ldots \ldots \ldots \ldots \ldots \ldots \ldots \ldots$ & $0,14 \mathrm{~m}^{3}$ \\
\hline Brasil $\ldots . . . \ldots$. & $0,096 \mathrm{~m}^{3}$ \\
\hline Venezuela & $0,05 \mathrm{~m}^{3}$ \\
\hline
\end{tabular}

FONTE: Moosmayer, 1977.

bricados da madeira; versatilidade da madeira na decoração de exteriores e interiores (Moosmayer, 1977)

Em 1974, a produção de madeiras das matas nativas no Brasil foi da ordem de $30.911 .791 \mathrm{~m}^{3}$ gerando um valor de 4.969.483 mil cruzeiros, sendo a região Norte (compreendendo os Estados do Pará, Amazonas, Acre e Territórios de Rondônia, Roraima e Amapá) responsável por $27 \%$ dessa quantidade e $19 \%$ do referido valor, estando em segundo lugar em contribuição, enquantơ que a primeira colocação foi para a região Sul com $42 \%$ e $54 \%$ respectivamente (Quadro V).

Observa-se que o valor do $\mathrm{m}^{2}$ da madeira é diferente para as distintas regiōes. Para o centro produtor localizado na região Sul é de cerca de 204,00 cruzeiros o $\mathrm{m}^{3}$ enquanto que para a região Norte é de 133,00 cruzeiros o $\mathrm{m}^{3}$, com uma desvalorização para menos de cerca de $45 \%$. A forma e métodos de extração, nesta última, são mais complexos, o que evidencia o baixo rendimento da produção.

A média das exportações mundiais de madeira, no período 1973/75 foi, segundo a FAO (Food and Agricultural Organization, órgão da ONU), de 2,5 bilhões de dólares. Nesse mesmo período, a média anual brasileira foi de 87,9 milhões de dólares, enquanto que foi de cerca de 635,4 milhões para a Malásia, 576,1 milhões para a Indonésia, 311,1 milhões para as Filipinas, 252,6 milhões de dólares para a Costa do Marfim e 145,5 milhões de dólares para o Gabão (Madeira,... 1978).

As exportações de madeiras na Amazônia em 1976 foram da ordem de 36.284 mil dólares, sendo o segundo produto que mais divisas gerou para a região, só suplantado pelo minério de manganês do Território Federal ao Amapá. É um produto de significativa exportação em todas as unidades da Amazônia Clássica representando $18 \%$ do total das exportações naquele ano (Quadro VI).

\section{O SETOR MADEIREIRO NO ESTADO DO AMAZONAS}

O Setor madeireiro no Estado do Amazonas se comporta, de um modo geral, nos mesmos moldes como o apresentado pela região como um todo.

QUADRO $v$

Produção de madeiras das matas nativas do Brasil, (I) segundo as regiões, 1974.

\begin{tabular}{|c|c|c|c|c|c|}
\hline \multirow[b]{2}{*}{ Regiões } & \multirow[b]{2}{*}{ Quant. $\mathrm{m}^{3}$} & \multicolumn{3}{|c|}{ Produção de madeiras } & \multirow{2}{*}{$\begin{array}{c}\text { Valor do } \\
\mathrm{m}^{3} \\
\text { Cr\$ } 1.000\end{array}$} \\
\hline & & $\%$ & $\begin{array}{l}\text { Valor em } \\
\text { Cr\$1.000 }\end{array}$ & $\%$ & \\
\hline Norte $\ldots \ldots \ldots \ldots \ldots$ & 8.357 .509 & 27,04 & 946.352 & 19,04 & 113,00 \\
\hline Nordeste $\ldots \ldots \ldots \ldots$ & 4.139 .012 & 13,39 & 453.322 & 9,12 & 109,00 \\
\hline Sudeste $\ldots \ldots \ldots \ldots$ & 2.185 .100 & 7,07 & 280.111 & 5,64 & 128,00 \\
\hline Sul $\ldots \ldots \ldots \ldots \ldots$ & 13.148 .436 & 42,53 & 2.681 .509 & 53,96 & 204,00 \\
\hline Centro Oeste $\ldots \ldots \ldots$ & 3.081 .734 & 9,97 & 608.189 & 12,24 & 197,00 \\
\hline BRASIL $\ldots \ldots \ldots \ldots \ldots$ & 30.911 .791 & 100,00 & 4.969 .483 & 100,00 & 161,00 \\
\hline
\end{tabular}

FONTE : Fundação Instituto Brasileiro de Geografia e Estatística, Anuório Estatíst co, 1976.

(1) Exceto lenha e carvão vegetal. 
Exportação da Amazônia, segundo os principais produtos - 1976, valor em US\$1.000,00 FOB.

\begin{tabular}{|c|c|c|c|c|c|c|c|c|}
\hline PRODUTOS & PARA & AMAZONAS & ACRE & AMAPA & RORAIMA & RONDÔNIA & TOTAL & $\%$ \\
\hline Minério de Manganês... & - & - & - & 63.381 & - & - & 63.381 & 31,38 \\
\hline Madeira $\ldots \ldots \ldots \ldots$ & 26.570 & 2.626 & 74 & 6.358 & 589 & 67 & 36.284 & 17,96 \\
\hline Pimenta $\ldots \ldots \ldots \ldots$ & 32.822 & - & - & - & - & - & 32.822 & 16,25 \\
\hline Castanha do Brasil .... & 14.529 & 7.183 & - & - & - & 457 & 22.169 & 10,98 \\
\hline Palmitos em Conserva. & 11.580 & - & - & - & - & - & 11.580 & 5,73 \\
\hline Peixes congelados .... & 7.832 & - & - & - & - & - & 7.832 & 3,88 \\
\hline \multirow{2}{*}{ Outros Pro } & 11.303 & 16.302 & 7 & 29 & 105 & 167 & 27.913 & 13,82 \\
\hline & 104.636 & 26.111 & 81 & 69.768 & 694 & 691 & 201.981 & 100,00 \\
\hline
\end{tabular}

FONTE : Exportação da... etc., 1977.

A produção média de madeiras no período 70/75 para o Estado do Amazonas foi da ordem de $89.223 \mathrm{~m}^{3}$ com um valor médio de 4.347 mil cruzeiros, representando o quinto produto dentro do extrativismo vegetal que contribuiu para formação da produção interna do Estado (Quadro VII).

A exploração madeireira é uma atividade executada em todas as micorregiões do Estado constituindo fonte de divisas para os municípios e de absorção e fixaçãơ de mão-deobra rural. As microrregiões que mais contribuiram para a produção estatal em 1975 foram: Solimões-Japurá com $43.000 \mathrm{~m}^{3}$ e um valor de 3.111 mil cruzeiros, seguida do Médio Amazonas com $31.000 \mathrm{~m}^{3}$ e $2.491 \mathrm{mil}$ cruzei-

\section{QUADRO VII}

Estado do Amazonas

Extrativismo vegetal, segundo os produtos

\begin{tabular}{|c|c|c|c|}
\hline \multirow[b]{2}{*}{ PRODUTOS } & \multicolumn{2}{|c|}{ Média no periodo $1970 / 75$} & \multirow[b]{2}{*}{$\%$} \\
\hline & Quant. Ton. & $\begin{array}{c}\text { Valor em } \\
\text { Cr\$ } 1.000 .00\end{array}$ & \\
\hline Borracha & 6.020 & 22.997 & 41,35 \\
\hline Castanha (hectol.) & 163.987 & 9.520 & 17,12 \\
\hline Guaraná & 202 & 8.004 & 14,39 \\
\hline Gomas não elást. & 4.438 & 7.777 & 13,98 \\
\hline Madeiras $\left(\mathrm{m}^{3}\right)$ & 89.223 & 4.347 & 7,82 \\
\hline Piaçava & 1.616 & 2.272 & 4,08 \\
\hline óleos de copaíba & 69 & 592 & 1,06 \\
\hline Cipó títica & 62 & 84 & 0,15 \\
\hline Diversos & 0,3 & 29 & 0,05 \\
\hline
\end{tabular}

FONTE: CODENYA - Anuório Estatístico, 1975. ros, Purus com $24.000 \mathrm{~m}^{3}, 1.351 \mathrm{mil}$ cruzeiros e Alto Solimões com $23.000 \mathrm{~m}^{3}$ e um valor de $2.482 \mathrm{mil}$ cruzeiros (Quadro VIII).

A indústria madeireira e mobiliária no Estado do Amazonas em 1976, estava constituída de cerca de 151 estabelecimentos constituindo $22 \%$ do total de outros ramos indus. triais e a que congregava o maior número de estabelecimentos. Absorvendo, em média, $57,7 \%$ de mão-de-obra por indústria, o que representa um número bastante significativo, respondendo por $18 \%$ do total de mão-de-obra empregada nos outros ramos industriais $e$ ainda o maior percentual de emprego por indústria, (Quadro $[X$ ) sem levar em consideração a mão-de-obra extrativa que constitui a ocupação principal em toda a área rural amazonense.

A indústria madeireira no Amazonas, segundo as principais linhas de produtos, assim se distribui (CEAG-AM, 1977).

Madeiras serradas ........... $26,2 \%$

Esquadrias em geral, estrutura de madeira, artigo de carpintaria $28,2 \%$

Caixões mortuários .......... 1,9\%

Caixas .................. 1,0\%

Tábuas, pernamancas, ripas, pranchões, vigamentos, lambris, tacos, cimalhos, Saltos de calçados . ..................

Compensados, chapas de compensadors, laminados ......... 5,8\%

Observa-se que ainda uma grande percentagem de indústrias operam com madeiras serradas simplesmente. 
QUADRO VIII

Estado do Amazonas

Extrativismo vegetal, produção segundo as microrregióes, 1975.

\begin{tabular}{|c|c|c|c|c|c|c|c|c|c|c|c|c|}
\hline \multirow{2}{*}{ Microrregiōes } & \multicolumn{2}{|c|}{ Borracha } & \multicolumn{2}{|c|}{ Gomas não elástica } & \multicolumn{2}{|c|}{ Madeiras } & \multicolumn{2}{|c|}{ Castanha } & \multicolumn{2}{|c|}{ Óleo de Copaíba } & \multicolumn{2}{|c|}{ OUTROS } \\
\hline & $\begin{array}{c}\text { Quant. } \\
\text { ton. }\end{array}$ & $\begin{array}{c}\text { Valor } \\
\text { Cr\$1.000 }\end{array}$ & $\begin{array}{c}\text { Quant. } \\
\text { ton. }\end{array}$ & $\begin{array}{c}\text { Valor } \\
\text { Cr\$ } 1.000\end{array}$ & $\begin{array}{l}\text { Quant. } \\
1.000 \mathrm{~m}^{3}\end{array}$ & $\begin{array}{c}\text { Valor } \\
\text { Cr\$1.000 }\end{array}$ & $\begin{array}{l}\text { Quant. } \\
1.000 \\
\text { hecto. }\end{array}$ & $\begin{array}{c}\text { Valor } \\
\text { Cr\$1.000 }\end{array}$ & $\begin{array}{c}\text { Quant. } \\
\text { ton. }\end{array}$ & $\begin{array}{c}\text { Valor } \\
\text { Cr\$1.000 }\end{array}$ & $\begin{array}{c}\text { Quant. } \\
\text { ton. }\end{array}$ & $\begin{array}{c}\text { Valor } \\
\text { Cr\$1.000, }\end{array}$ \\
\hline Alto Solimões . & 231 & 1.581 & 25 & 74 & 23 & 2.482 & 1 & 95 & 1 & 4 & - & - \\
\hline Juruá $\quad \ldots \ldots \ldots \ldots \ldots$ & 1.425 & 9.775 & 254 & 755 & 3 & 301 & - & - & - & - & - & - \\
\hline Purus & 1.122 & 7.504 & 816 & 2.426 & 24 & 1.351 & 46 & 3.070 & 0,4 & 2 & - & - \\
\hline Madeira $\ldots \ldots \ldots \ldots$ & 491 & 3.419 & 490 & 1.461 & 6 & 292 & 25 & 1.919 & 8 & 63 & - & - \\
\hline Rio Negro & 109 & 559 & 403 & 1.187 & 3 & 276 & 3 & 2.098 & 2 & 15 & 1.503 & 3.327 \\
\hline Solimões-Japurá & 285 & 1.902 & 310 & 931 & 43 & 3.111 & 31 & 2.414 & 1 & 5 & - & - \\
\hline Médio Amazonas ...... & 162 & 982 & 558 & 1.673 & 31 & 2.491 & 58 & 4.562 & 10 & 61 & 2 & 13 \\
\hline
\end{tabular}

FONIE: CODEAMA - Anuório Éstotístico, 1975. 
QUADRO IX

Estado do Amazonas

Número de estabelecimentos e número médio de operários.

\begin{tabular}{|c|c|c|c|}
\hline Gênero de Indústria & $\begin{array}{c}\text { N. } .^{\circ} \\
\text { estabel. }\end{array}$ & $\begin{array}{l}\text { Média de } \\
\text { Operários }\end{array}$ & $\%$ \\
\hline Extração de Minerais ....... & 12 & 26,4 & 1,04 \\
\hline $\begin{array}{c}\text { Produção de Minerais n/Metá- } \\
\text { licos } \ldots \ldots \ldots \ldots \ldots \ldots \ldots\end{array}$ & 66 & 20,9 & 4,56 \\
\hline Metalúrgica $\ldots \ldots \ldots \ldots \ldots$ & 74 & 14,2 & 3,48 \\
\hline Mecânica $\ldots . . . \ldots \ldots \ldots \ldots$ & 16 & 12,1 & 0,64 \\
\hline Mat. Elétrico e de Comunicação & 32 & 156,5 & 16,51 \\
\hline Material de Transporte ...... & 22 & 77 & 5,58 \\
\hline Madeira $\ldots \ldots \ldots \ldots \ldots$ & 103 & 49,2 & 16,72 \\
\hline Mobiliário .............. & 48 & 8,4 & 1,34 \\
\hline Papel e Papelão $\ldots . . \ldots \ldots$ & 4 & 9,7 & 0,13 \\
\hline Borracha $\quad \ldots \ldots \ldots \ldots \ldots \ldots$ & 11 & 28,7 & 1,04 \\
\hline $\begin{array}{r}\text { Couros e Peles e Produtos Si } \\
\text { milares } \\
\ldots \ldots \ldots\end{array}$ & 3 & 107,3 & 1,06 \\
\hline Química $\ldots \ldots \ldots \ldots \ldots \ldots$ & 16 & 47,7 & 2,52 \\
\hline $\begin{array}{l}\text { Produtos Farmacêuticos e Ve } \\
\text { terinários } \ldots \ldots \ldots \ldots \ldots \ldots \ldots\end{array}$ & 2 & $s / i$ & - \\
\hline Perfumarias, Sabões \& Velas.. & 5 & 106,4 & 1,75 \\
\hline Produção de Matéria Plástica. & 9 & 52,4 & 1,56 \\
\hline Têxtil $\ldots \ldots \ldots \ldots \ldots \ldots \ldots$ & 17 & 257,7 & 14,44 \\
\hline $\begin{array}{c}\text { Vestuário, Calçados e Artigos } \\
\text { de Tecido } \ldots \ldots \ldots \ldots \ldots\end{array}$ & 29 & 43,4 & 4,15 \\
\hline Produtos Alimentares $\ldots \ldots \ldots$ & 132 & 28,1 & 12,21 \\
\hline Bebidas $\ldots \ldots \ldots \ldots$ & 11 & 116,4 & 4,22 \\
\hline Fumo $\ldots \ldots \ldots \ldots \ldots$ & 1 & 22 & 0,07 \\
\hline Editorial e Gráfica ... & 40 & 2,4 & 0,32 \\
\hline Diversos $\ldots \ldots \ldots$ & 48 & 42,1 & 6.66 \\
\hline Total. & 701 & 43,3 & 100,00 \\
\hline
\end{tabular}

FONTE: CEAG-AM - Codastro Industrial do Amazonas, $76 / 77$ (1977).

O Estado do Amazonas exportou para o exterior em 1976, cerca de 26.111 mil dólares sendo a madeira o terceiro produto na pauta das exportações, contribuindo com $2.626 \mathrm{mil}$ dólares. Os principais mercados importadores foram os Estados Unidos (41\%), Reino Unido $(15 \%)$, Alemanha Ocidental $(9 \%)$, Argentina $(7 \%)$, França $(4 \%)$ (Quadro $X$ e XI).

Nas exportações interestaduais por cabotagem, a madeira ocupou a $6^{\mathrm{a}}$ (sexta) colocação com 17.246 toneladas e um valor de $42.718 \mathrm{mil}$ cruzeiros (Quadro XII) .

Os produtos de madeiras fabricados no Amazonas sofrem a concorrência de produtos similares fabricados em outros estados, bem como dos sucedâneos na construção civil, cuja importação foi facilitada pela Zona Franca de Manaus. Os preços oferecidos pelos produtos amazonenses não são competitivos com os produtos de outros Estados, por isso o Amazonas importa tacos do Pará.

Ainda, a falta de inovações tecnológicas dos produtos de madeira, a falta de renovação dos métodos de produção e, realisticamente, a relativa deficiência na capacidade gerêncial do setor, foram apontados pelo Diagnóstico Setorial das Indústrias de Serrarias do Estado

\section{QUADRO X}

Estado do Amazonas

Exportação para o exterior segundo os principais produtores

\begin{tabular}{|c|c|c|}
\hline PRODUTOS & $\begin{array}{l}\text { Valor US\$ } \\
1.000 \text { FOB }\end{array}$ & $\%$ \\
\hline & 7.183 & \\
\hline $\begin{array}{l}\text { Castanha do Brasil } \ldots \ldots \ldots \ldots \ldots \\
\text { Produtos Químicos e Preparados }\end{array}$ & & 27,51 \\
\hline n/compra em outra parte ..... & 4.303 & 16,48 \\
\hline Madeira $\ldots \ldots \ldots \ldots \ldots \ldots \ldots$ & 2.626 & 10,06 \\
\hline $\begin{array}{l}\text { Costumes, Uniformes Militares, } \\
\text { Casaco, Blusão, Capa, Calça... }\end{array}$ & 2.264 & 8,67 \\
\hline Tecido de Juta, liso, cru ....... & 1.651 & 6,32 \\
\hline Outros $\ldots \ldots \ldots \ldots \ldots \ldots \ldots$ & 8.084 & 30,96 \\
\hline Total & 26.111 & 100,0 \\
\hline
\end{tabular}

FONTE : Exportação da... etc., 1977.

\section{QUADRO XI}

Estado cio Amazonas

Destino das Exportações, 1976

\begin{tabular}{|c|c|c|}
\hline Destino & US\$ 1.000 & $\%$ \\
\hline Estadios Unidos & 10.753 & 41,18 \\
\hline Reino Unido $\ldots \ldots \ldots \ldots$ & 3.989 & 15,28 \\
\hline Alemanha Ocidental $\ldots \ldots \ldots \ldots$ & 2.250 & 8,62 \\
\hline Argentina $\quad \ldots \ldots \ldots \ldots \ldots \ldots$ & 1.721 & 6,59 \\
\hline França $\ldots \ldots \ldots$ & 1.124 & 4,30 \\
\hline Outros $\ldots \ldots \ldots \ldots \ldots$ & 6.273 & 24,03 \\
\hline Total............... & 26.111 & 100,00 \\
\hline
\end{tabular}

FONTE : Exportação da... etc., 1977. 


\begin{tabular}{|c|c|c|c|c|}
\hline PRODUTOS & $\begin{array}{c}\text { Quantid. } \\
\text { (t) }\end{array}$ & $\%$ & $\begin{array}{c}\text { Valor } \\
\text { Cr\$ } 1.000\end{array}$ & $\%$ \\
\hline Juta em bruto e preparaie. & 24.623 & 12,86 & 247.414 & 26,12 \\
\hline Gasolina comum e a granel....$\ldots$. & 26.689 & 13,94 & 78.100 & 8,25 \\
\hline Wleo $\mathrm{p} /$ motores de explosão $\ldots . . . .$. & 42.221 & 22,05 & 51.629 & 5,45 \\
\hline Estanho em bruto e s/ligas ... & 710 & 0,37 & 46.694 & 4,92 \\
\hline Borracha $\ldots \ldots \ldots \ldots \ldots \ldots \ldots \ldots \ldots$ & 3.245 & 1,69 & 46.443 & 4,90 \\
\hline Madeira não especificada em bruto e preparada ..... & 17.246 & 9,01 & 42.718 & 4,51 \\
\hline Produtos detergentes e emulsivos não especificados... & 6.402 & 3,34 & 37.591 & 3,97 \\
\hline Tecidos de outras fibras artificiais ou sintéticas...... & 203 & 0,11 & 30.853 & 3,26 \\
\hline Outros $\ldots \ldots \ldots \ldots \ldots \ldots \ldots \ldots \ldots \ldots \ldots \ldots$ & 70.167 & 36,63 & 365.825 & 38,62 \\
\hline 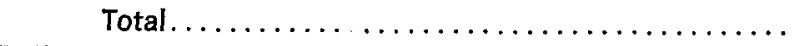 & 191.506 & 100,00 & 947.222 & 100,00 \\
\hline
\end{tabular}

FONTE : CODEAMA - Anuário Estatistico, 1975.

do Amazonas (CEAG-Am, 1975) como responsáveis pelo estrangulamento nas indústrias de serrarias do Estado.

O destino das exportações nacionais é principalmente o Nordeste sendo o Estado do Ceará o grande importador seguido pelo Rio Grande do Norte, Maranhão e ainda, São Paulo, Paraíba, Rio de Janeiro e Pernambuco (idem).

\section{CONSIDERAÇÕES FINAIS}

O prévio diagnóstico revela a importância da incipiente indústria madeireira na frágil economia regional e também confirma que a região mal deu início ao aproveitamento dos seus recursos florestais, no conceito da moderna tecnologia da madeira com empreendimentos florestais integrados, aglutinados em distritos florestais e, em escala suficiente, que propicie o aparecimento de economia de escala e de localização, favorecendo a çriação de complexos técnicos madeireiros, com suas conseqüências acumulativas para a sociedade como é mostrado ne figura 1.

O que se observa, no entanto, é a devastação da floresta causada pela pecuária incentivada pela agricultura itinerante e a sua descapitalização e desperdício, decorrente da exploração florestal em áreas não localizadas, da tecnologia empregada na extração e transformação da madeira, assim como a quase inexistência de manejo e ordenamento florestal.
No que diz respeito aos custos sociais da devastação causada pelos desmatamentos com fins de projetos agropecuários incentivado. Mahar (1978) considera que evidentemente não seriam nulos, pois incluem o valor da madeira perdida somado ao esgotameno dos solos que normalmente acompanha este tipo de atividade nas regiōes tropicais. Considera o mesmo autor que os custos do esgotamento dos solos são difíceis de quantificar, mas afirma ser possivel obter uma aproximação do custo do desmatamento multiplicando o volume estimado de madeira perdida pelo seu preço médio de mercado. Para os projetos agropecuários incentivados, calcula Mahar (1978), que a perda de madeira foi da ordem de 432 milhões de metros cúbicos. Sobre este volume ele atribuiu moderadamente um preço médio da lenha na Amazônia, em 1974. Efetuando este cálculo, o autor chegou à conclusão de que o custo social foi da ordem de US\$ 1 bilhão, importância essa, que, na sua opinião, são duas vezes o investimento total, realizado por todos os projetos pecuários entre 1966/1975.

Em relação ao vandalismo contra a floresta causado pela agricultura itinerante, os exemplos estão vivos, são claros e insofismáveis, bastando que o interessado percorra as regiōes cortadas pelas estradas de penetrações ou visite a região Bragantina no Pará ou Manaus-Itacoatiara no Amazonas, para observar os imensos capoeirões resultantes desta ati- 


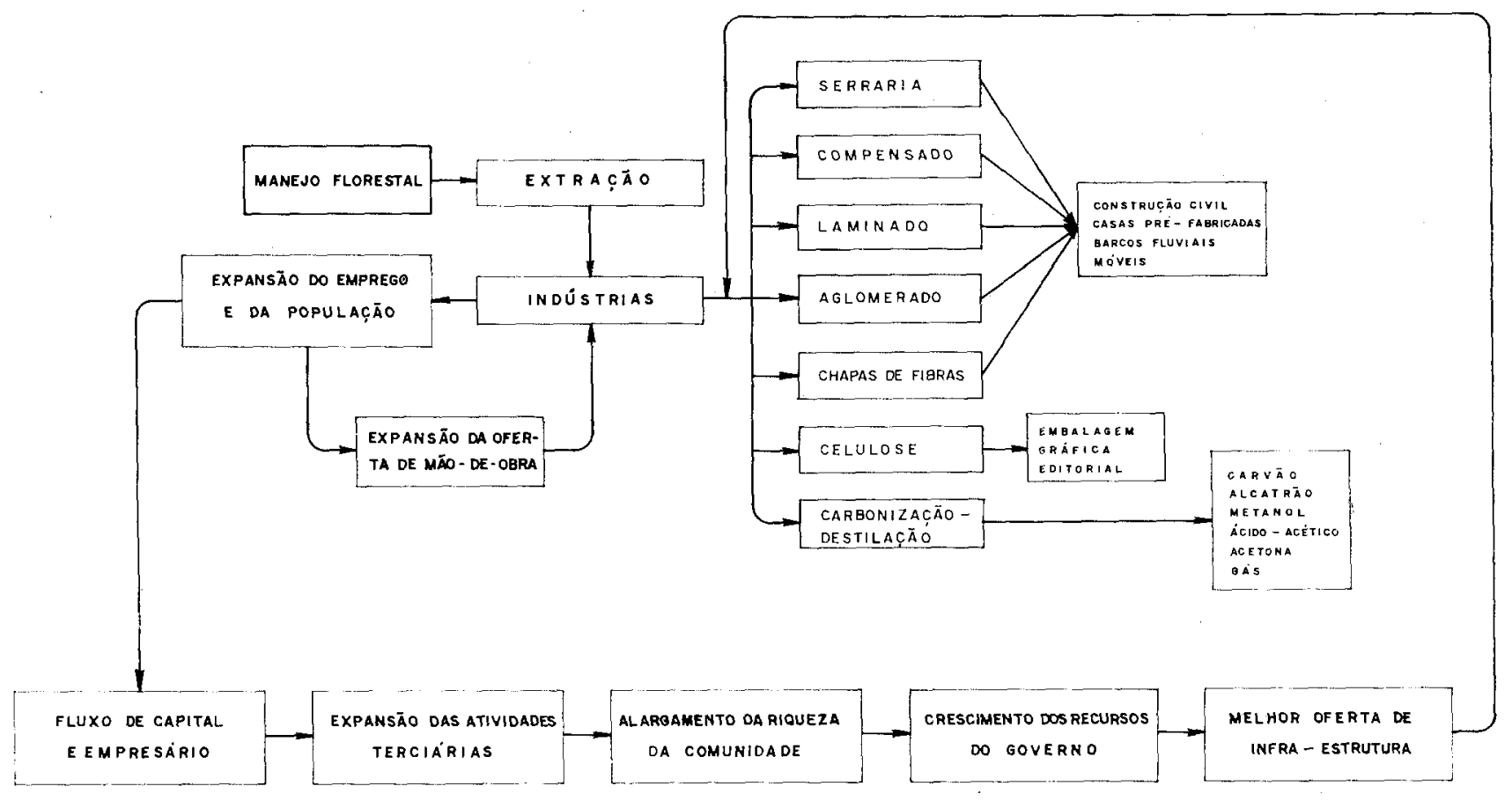

Fig. 1 - Síntese diagramático do processo de causação cumulativa de um complexo técnico madeireiro.

vidade predatória e sem nenhum significado econômico, porque geralmente são atividades de subsistência.

Das três atividades básicas do setor primário: Agricultura, Pecuária e Extrativismo madeireiro, a que menos causa danos na ambiência florestal da Amazônia é a do setor madeireiro, em decorrência do aspecto seletivo em que se processa a extração madeireira, isto é, a atividade exploratória madeireira não se processa através do "corte raso" seguida do encoivaramento como na agricultura e pecuária, mas ela é seletiva e exclusiva, porque somente corta aquelas espécies de real valor comercial, sendo excluída e permanecendo na floresta as demais espécies; isto faz com que a floresta não perca a sua dasonomia, entretanto, tem a capacidade de empobrecer economicamente o bosque por causa das retiradas das espécies mais nobres.

Acarreta este tipo de exploração a rigidez na elasticidade da oferta das madeiras e em conseqüência a elevação dos seus preços, dado o empirismo da extração e transporte. Por outro lado, em conseqüência da descapitalização das matas nativas mais próximas dos centros de beneficiamento de madeira, faz com que cada vez mais aumente a distância entre os centros de industrialização e o da extração. O exemplo mais típico é a da indústria madeireira do Estado do Amazonas, cuja maioria das unidades de produção se encontra em Manaus e as áreas de exploração florestal nos altos rios a mais de $1.000 \mathrm{~km}$ de distância .

\section{CONCLUSÃO}

1. A despeito das vantagens que a região oferece para o desenvolvimento da indústria florestal, a mesma é ainda subdesenvolvida e basicamente alicerçada no extrativismo vegetal, sem manejo ou ordenamento florestal, salvo raras exceções, de maneira idêntica ao observado no passado remoto.

2. Mesmo sendo subdesenvolvida, o setor madeireiro é um dos componentes importantes na economia regional para a geração de renda e manutenção do emprego.

3. As atividades do setor primário que mais têm devastado a floresta é a pecuária incentivada e a agricuitura itinerante. 
4 A exploração madeireira, na sua forma atual, não destrói a floresta, simplesmente descapitaliza-a das espécies nobres, entretanto dificulta a expansão do setor dado o empirismo da extração e no transporte e, por estar a atividade manufatureira grandemente pulverizada.

\section{Bibliografia}

\section{CEAG-AM}

1975 - Diagnóstico setorial da indústria de serraria do Estado do Amazonas, SUFRAMA, $227 p$.

1977 - Cadastro industrial do Amazonas. Editora Umberto Calderaro. 466p.

\section{CODEAMA}

1967 - Anuário Estatístico, v. 6, Governo do Estado do Amazonas. 303p.

Dubors, J. A.

1975 - A floresta Amazônica e a sua utilização face aos princípios modernos de conservação da natureza. In: Atas do Simpósio sobre a Biota Amazônica, 7 (Conservação da Naturoza : recursos naturais): 115-145.

\section{EMBRAPA}

1974 - Anteprojeto da implantação do Centro de Pesquisas para o desenvolvimento dos resursos da Aniazônia. 301p.

Exportações da Amazônia: REALIDAde e POTENClaldDade 1977 - Amazônia, 3 (31): 14-20.
FUNDAÇÃo I.B.G.E.

1976 - Anuário Estatístico, Rio de Janeiro.

GUERRA, F.

1977 - Produção de álcool anidro a partir da madeira. Silvicultura, 1 (4): 34-35.

MADEIRA GRANDE POTENCIAL ATNDA POUCO APROVETTADO 1978 - Amazônia, 3 ،34): 6-8.

MAfIAR, D. J.

1978 - Desenvolvimento econômico da Amazônia, uına análise das políticas governamentais. Relatório de pesquisa n. 39 , Rio de Janeiro, IPEA/INPES. 259p.

MOOSMAYER, II.

1977 - "Wood is wonderful". Brasil Madeira, 1 (i1): 50p.

SUDAM

s/d - a - Pesquisa, instrumental básico para o planemento regional, SUDAM, Dept. de Recur sos Naturais, Belém, 51p. ilustr.

1973b- Estudos básicos para o estabelecimento de uma política de desenvolvimento dos re. cursos florestais e de uso racional das terras na Amazônia. Ministério do Interior SUDAM, Dept. de Recursos Naturais, Belém. $52 p$.

1973c - Tecnologia de produtos florestais na Amazônia. Ministério do Interior, SUDAM, Dept. de Recursos Naturais, Belém. 42p.

VOLATRON, B.

1976 - La mise en valeur des richesses forestieres en Amazonie Bresilienne et en Colombie. Bois et forêts des Tropiques, (165): 60-75. 